\section{Space-time proceedings}

Asymptotic Structure of Space-Time. Edited by F. Paul Esposito and Louis Witten. Pp. vii + 442. (Plenum : London and New York, 1977.) \$51.

IN recent years it has increasingly become the practice for the proceedings of international scientific conferences to be published a year or so later in a single volume at an exorbitant price. Occasionally these collected works are very useful as a comprehensive review of a new or rapidly developing subject, and if well written and edited can provide students with a convenient access to up-to-date work. All too often, however, the proceedings are a hotchpotch of incomplete articles, bearing only a superficial connection to each other, and coexisting under the same cover merely to avoid offending some of the conference contributors.

The usefulness of conference proceedings is still further reduced when preprints of the papers are thoroughly circulated beforehand and all the publisher does is to bind together reproductions of these manuscripts (often containing barely legible hand-written mathematical symbols and a multiplicity of type faces) and offer the endproduct for anything up to a few dozen dollars.

Many of these volumes are now being offered to university libraries labouring under stringent budget controls, so that would-be purchasers are becoming much more discerning in their requirements. They will be interested to know that Asymptotic Structure of Space-Time is, by these recent standards, very well put together. True, the price, at $\$ 51$, is regrettably high, but most of the manuscripts have been well prepared and typed, and the papers are of a fairly uniform style and standard. The conference took place in Cincinnati in June 1976, and covers a selection of important and fast-moving new developments in mathematical relativity and space-time structure. After a useful and well written introduction by R. Geroch the reader is treated to a discourse on cone space, (Brian Bramson), conformal bundle boundaries (B. G. Schmidt) and complex vacuum metrics (J. F. Plebanski and I. Robinson). I was disappointed that the theory of twistors did not receive some prominence, but there are two good papers on the related topic of $\mathrm{H}$-space (E. T. Newman, K. P. Tod and M. Ko), although these are far too condensed.

The recent resurgence of interest in quantum aspects of gravitation is reflected in a (once again, too short) paper on supersymmetry by $\mathbf{P}$. van Nieuwenhuizen, together with an excellent and very readable review on quantum field theory in curved space and particle production by gravitational fields, by Leonard Parker. I found this one of the best presented of all the papers, and its list of 168 references is a masterpiece of literature research.

My overall impression of this book is that it is well edited and presented, and is nice to have available.

Paul Davies

Paul Davies is Lecturer in Mathematics at King's College, University of London, UK.

\section{Methylmercury intoxication}

Minamata Disease: Methylmercury Poisoning in Minamata and Niigata, Japan. Edited by $\mathrm{T}$. Tsubaki and $\mathrm{K}$. Irukayama. Pp. 310. (Kodansha: Tokyo; Elsevier: Amsterdam, New York and Oxford, 1977.) \$48.25; Dfl. 118.

METHYLMERCURY intoxication is now frequently called Minamata disease as it was first around the Minamata Bay that methylmercury caused a mass epidemy. One of the best parts of the book deals with the background and epidemiology of this and a similar epidemy in Niigata. The Minamata epidemy started in 1941 with individual cases and its epidemic proportion was noticed in 1956 when it was first believed to be of infectious origin. In $1958 \mathrm{Dr}$ McAlpine, who saw some of the patients, called attention to the similarity between Minamata Disease and methylmercury intoxication. His paper written with Dr Àraki and published in the Lancet in 1958, but not mentioned in the otherwise detailed historical and clinical account, turned the attention to mercury; and subsequently methylmercury was indentified in sediments, seafood and in the drainage system of the Minamata factory.

Although the number of yearly cases declined, new cases were reported as late as 1972-73, which is not surprising as the mercury concentration in shellfish remained up to that period of about 5 p.p.m., but sometimes as high as 16 p.p.m. The situation was not very different in Niigata, where the ban on fishing in the Agano river did not prevent new outbreaks, which are discussed in this book as intoxications with delayed onset. Whether methylmercury is able to precipitate disease long after the cessation of exposure is an important problem, but inadequately handled in the whole book. There is also a certain reluctance to re-value past views: data based on the dithizone method is interpreted without reservation although according to a table this method, compared with atomic absorption, generally underestimated tissue mercury levels by a factor of 3 .

Translation is very uneven and often puzzling. A sentence like "After an interval of 14 years, one of the 4 cases came to necropsy, and was found to be grossly ataxic; blindness of the left eye and severe constriction of the visual field in the right eye persisted" is more than a puzzle, but it might illustrate the difficulty of interpreting some paragraphs with less blatant error. It might be that the translation is responsible for the surprising statement that mercury half-time in the brain was calculated from autopsy material.

Despite shortcomings, Minamata Disease is an important publication on the origin, epidemiology, pathology and clinical aspects of the two outbreaks in Japan. It would be a very much better book, however, if publications of this type were submitted to the same rules as any publication in a learned journal: revision based on the suggestions and criticisms of two referees.

Laszlo Magos

Laszlo Magos is Senior Scientific Officer at the MRC Toxicology Unit, Carshalton, UK.

\section{BOOKS ON PURE AND APPLIED SCIENCE}

Books reviewed or mentioned in this journal are available from stock.

Catalogues on application. Please state interests.

\section{SCIENTIFIC LIBRARY}

ANNUAL SUBSCRIPTION from $£ 7.00$

Reduced rates for multiple subscriptions Available in U.K. only

Prospectus free on request

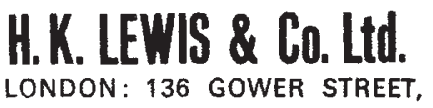
WC1E 6BS

Telephone : $01-3874282$ 